\title{
REVERSING THE TELESCOPE:
}

\section{EVALUATING NGO PEER REGULATION INITIATIVES}

\author{
Dr Angela M. Crack
}

\begin{abstract}
This article investigates perceptions of the extent to which NGO peer regulation initiatives have been effective in enhancing accountability in the humanitarian sector. It is based upon semi-structured interviews with individuals with responsibility for accountability policy from leading NGOs and focuses on two of the best-known initiatives: Humanitarian Accountability Partnership and Sphere. It finds that the initiatives have prompted positive changes in practice, but there are significant concerns about their deleterious impacts. Participants describe a host of challenges, including the tendency of peer -regulation to become excessively bureaucratic and labor-intensive. They cast some doubt on the potential of the initiatives to assist NGOs to be more accountable to affected communities.
\end{abstract}

Key Words: NGO, accountability, regulation. 
Accountability has become the leitmotif of debate about principles of good practice for nongovernmental organizations (NGOs). It was once relatively easy for NGOs to escape scrutiny of their actions by sheltering behind the flattering caricature of being a 'magic bullet' for a host of societal ills (Edwards and Hulme, 1996). The push for enhanced accountability emerged in the wake of the Cold War, when Northern governments and international organizations increasingly turned to NGOs to provide emergency assistance in the Balkans and global South. These donors demanded greater financial transparency from NGOs and evidence that programs met their intended objectives (Crack, 2013a). The sector has also recently been rocked by a series of high-profile scandals, and unsympathetic media coverage (Gibelman \& Gelman, 2001). A legacy of botched relief operations, from Rwanda to Haiti, has evoked concerns that NGOs could worsen the plight of vulnerable people who they aim to assist (The Lancet, 2010). NGOs are exposed as never before to allegations of corruption, incompetence and abuse of power.

There is widespread agreement amongst practitioners, donors and academics that NGOs should strive to provide assurance that they are 'accountable' actors (Groves \& Hinton, 2004; Jordan \& van Tujl, 2007, Kilby, 2006). It is commonly asserted that NGOs have multiple (and often conflicting) accountability relationships. These include 'upwards accountability' to governments and donors, 'downwards accountability' to affected communities and partners, 'internal accountability' to staff, and 'peer accountability' to the wider sector (Edwards and Hulme, 1996; Najam, 1996; Ebrahim, 2003; Crack, 2013b). Peer regulation initiatives $^{i}$ are the most significant collective attempt to promote these ideals. Peerregulation is the process whereby a sector level organization promotes common standards of quality and accountability for NGOs. NGOs may volunteer to adhere to these standards, but they are not under any legal obligation. Peer-regulation ranges from aspirational codes of conduct, to certification initiatives with robust verification procedures (Lloyd \& Casas, 2005). Lloyd et al (2010) have identified over 350 peer regulation initiatives, which spans a range of NGO activities, such as service delivery, advocacy and fundraising. They were first established, and are most developed, in humanitarian work. This research focuses on the Humanitarian Accountability Partnership (HAP) and Sphere - two of the best-known initiatives for humanitarian NGOs that focus strongly on downwards accountability, and represent both ends of the regulatory spectrum. 
Literature on the topic is scarce. There are some useful practitioner-oriented publications on peer-regulation, but not specific comparisons of HAP and Sphere (ibid; Hammand \& Morton, 2011; Featherstone, 2013). There has been some journal articles on the effectiveness of national and regional peer-regulation, but again, these do not focus on the sector-wide initiatives (Bies, 2010; Gugerty, 2008; Sidel, 2010). Some practitioners who were closely involved with early discussions about Sphere have published their reflections, but these are now rather outdated since they relate to earlier versions of the project (Darcy, 2004; Dufour et al, 2004; Gostelow, 1999; Tong, 2004). Most scholarly activity clusters around the reasons behind the emergence of peer-regulation, which can be crudely characterized as a debate between sociological institutionalists/constructivists (Kennedy, 2012; Deloffre, 2010) and adherents of principal-agent theory (e.g. Prakash and Gugerty, 2010). There is barely any academic literature that evaluates the impact of HAP and Sphere policies. This is regrettable, given that representatives of HAP and Sphere have admitted that there is scant evidence of their impact in improving humanitarian assistance (ALNAP, 2012). This article aims to address that gap. It investigates perceptions of the extent to which HAP and Sphere have been effective in enhancing levels of accountability across the sector. It is based upon semistructured interviews with thirty-four individuals with responsibility for accountability policy from fourteen leading international humanitarian NGOs. Despite indications that these agents can be important policy entrepreneurs within NGOs and the wider sector, they have rarely been the subject of academic research. ${ }^{\text {ii }}$

The article consists of four main sections. First, there is an outline of the main features of HAP and Sphere, and details of the methodology. Second, there is discussion of the perceived benefits of peer-regulation, which include providing an impetus for change and a signal of credibility to donors. Third, the numerous challenges of peer-regulation are examined, which are as follows: there has been an overwhelming proliferation of initiatives, observance of the standards can be excessively bureaucratic, the initiatives may not adequately accommodate the organizational diversity in the sector, and the extent to which the standards are sufficient to embed a culture of accountability to affected populations is doubtful. Finally, the conclusion offers some policy prescriptions, reflects on the strengths and limitations of the research, and provides recommendations for further research. 


\section{THE SPHERE PROJECT}

Sphere is undoubtedly the best-known regulatory initiative: the standards 'have now entered into the lexicon of the aid community and the production of those standards has now entered into its folklore' (Walker \& Purdin, 2004: 100). Sphere proclaims it is 'working for a world in which the right of all people affected by disasters to re-establish their lives and livelihoods is recognized and acted upon in ways that respect their voice and promote their dignity and security' (Sphere, 2011)..It was launched in 1997 by the International Red Cross and Red Crescent Movement and a consortium of NGOs as an attempt to develop a code of conduct supported by technical guidance (Walker \& Purdin, 2004: 101). In the initial stages, a working group was established to create a Charter to codify norms about humanitarian action. The Humanitarian Charter emphasized the centrality of the humanitarian imperative, and declared the fundamental rights of crisis-affected people to receive assistance and to live a life with dignity. It stressed the importance of accountability to affected communities, and their participation in consultations about the provision of assistance. Several committees were tasked with drafting Minimum Standards for emergency response: information about practical action in relief programs that could help to achieve the normative goals outlined in the Charter. The discussions drew upon the expertise of numerous NGOs and intergovernmental agencies such as the UNCHR, WHO and WFP. The finalized version of the Humanitarian Charter and Minimum Standards was published in 2000 as the 'Sphere Handbook', containing information about best practice in emergency response, and was widely disseminated throughout the humanitarian community. The Handbook has since undergone two revisions based on exhaustive consultations with thousands of practitioners and hundreds of agencies. The 2011 printed edition stands at nearly 400 pages. It has sold tens of thousands of copies across the world, has been translated into 23 languages, and can also be accessed for free online. ${ }^{\text {iii }}$ Thus, there are firm grounds for Sphere to claim that it 'enjoys broad acceptance by the humanitarian sector as a whole' (Sphere, 2011: 5).

The Minimum Standards cover four areas of humanitarian assistance: water supply, sanitation and hygiene promotion; food security and nutrition; shelter, settlement and non-food items; and health action. The Standards are supported by lists of key indicators and guidance notes. For example, one of the Shelter and Settlement Standards states that people should have access to covered living space, that ensures 'their privacy, safety and health and enabl[es] essential household and livelihood activities to be undertaken.' (ibid: 258) One of the 
suggested indicators for meeting this Standard is that all 'affected individuals have an initial minimum covered floor area of $3.5 \mathrm{~m}^{2}$ per person' (ibid.).

NGOs can claim adherence to the Sphere Standards, but there is no formal system of accreditation or verification. Sphere has 'consciously opted for the Handbook not to be prescriptive or compliance-oriented, in order to encourage the broadest possible ownership of the Handbook' (ibid: 8). Numerous NGOs have incorporated Sphere Standards into their internal accountability frameworks, and designed their own systems of monitoring and evaluation to assess their practice. Institutional donors have also increasingly attached Sphere-related conditions to funds.

Sphere has not been met with an uncritical reception. From the earliest stages, a group of French NGOs, led by Médicins Sans Frontières, expressed grave skepticism about the entire enterprise, since they argued that it reduced humanitarianism from an act of compassion and solidarity, to merely an act of technical assistance (Dufour et al, 2004; Terry, 2002). They questioned the wisdom of determining common standards for humanitarian operations, since crises occur in hugely diverse cultural, economic and environmental contexts. Moreover, they feared that donors would use Sphere as a tool to impose more restrictive conditions on NGOs, designed to improve cost-efficiency rather than respond to the most compelling human needs (ibid). Two key figures in the development of Sphere have admitted that it has been sometimes 'hijacked and mugged' by donors, and that it can 'grossly fail to support the victims of war and disaster' if it is narrowly interpreted as a set of technical guidelines (Walker \& Purdin, 2004: 111). Nonetheless, they also point out that the 'rights-based approach' promoted by Sphere has been a significant influence on the conception and practice of humanitarian action since its inception (ibid: 110).

\section{HUMANITARIAN ACCOUNTABILITY PARTNERSHIP INTERNATIONAL}

(HAP)

HAP is one of the few certification schemes in the humanitarian sector, with international reach. It is a multi-agency initiative that aims to enhance the quality of humanitarian programs and the accountability of member organizations to crisis-affected populations. Accountability is defined as: 'the means through which power is used responsibly. It is a process of taking into account the views of, and being held accountable by, different 
stakeholders, and primarily the people affected by authority and power' (HAP, 2010: 1, original emphasis). HAP is designed to assist NGOs to be responsive to the needs of people and communities, and to reduce the potential for corruption and abuse. Although HAP is generally promoted as a tool for humanitarian accountability, the Standard states that the 'dividing line between humanitarian assistance and development assistance is fluid', and the term "'humanitarian" should be interpreted broadly' (HAP, 2010: 2). In fact, 'the HAP Standard can be applied to all aspects of an organization's work, including relief, development and advocacy' (ibid).

The first HAP Board was elected in 2003, at a General Assembly of representatives and Chief Executives of several NGOs. The HAP Principles were issued thereafter, which acknowledge the primacy of the humanitarian imperative, and the norms of participation, transparency, and the rights of redress, amongst others. A two-year consultation followed in 2005 to assess the suitability of introducing evidence-based indicators to enable organizations to demonstrate their observance of the Principles. HAP subsequently evolved into a formal accreditation system. The first version of the HAP Standard in Accountability and Quality Management was published in 2007, and it was updated in 2010 following a stakeholder consultation of 1,900 people in 56 countries, including 'beneficiaries' (ibid).

The Standard consists of six benchmarks, relating to corporate commitments, staff competency, information-sharing, participation, complaints procedures and organizational learning. Each benchmark is supplemented by a detailed list of verifiable requirements. There are additional clauses for NGOs that do not directly deliver assistance, but supply financial, material or technical support to partner organizations. These organizations are required to undertake specific measures to verify that their partners are also meeting the Standard, although some allowances are made to reflect differences in capacity (HAP, 2010: 3).

HAP awards certification to NGOs that are able to demonstrate accordance with the Standard through a rigorous independent audit. This includes scrutiny of internal documents, interviews with staff based at the headquarters and the field, interviews with partners and intended beneficiaries, and direct observation of practice. Certification expires after a three year period, during which time the NGO will undergo mid-term monitoring to verify continued adherence to the Standard. NGOs are supported in their efforts to improve their performance: HAP representatives are sent to the field to provide advice, there are training workshops, and a wealth of learning resources online. There is, however, a penalty for non- 
compliance. Complaints about the conduct of member organizations can be submitted to HAP's Standing Complaints Committee, and if upheld, certification can be revoked.

HAP has 91 member organizations, which include institutional donors as well as NGOs from across the world. Only 17 members have successfully completed the audit and are fully certified (HAP, 2014). As discussed below, some critics of HAP have alleged that there is insufficient evidence of its impact on standards of humanitarian accountability, but there are reasons to speculate that it has been widely perceived as beneficial. HAP conducted a recent survey of 756 members of the humanitarian community to collate views 'about organizational practice, including the levels of participation by disaster-affected communities in performance assessments, and the extent to which organizations foster an environment in which communities feel they can raise complaints' (HAP, 2012: 108). Respondents from HAP-certified NGOs gave the highest approval ratings for their organization's performance in humanitarian accountability (78.5\%), whilst respondents from NGOs unrelated to HAP gave the lowest ratings (36.6\%; ibid: 114). It should be noted, however, that these findings reveal an interesting correlation between perceptions of good accountability and HAP membership, rather than assertions by the respondents of a direct causal link. The fact that HAP conducted the survey is also potentially problematic and highlights the need for independent assessment.

\section{Main Characteristics of Sphere and HAP}

\begin{tabular}{|l|l|l|l|}
\hline $\begin{array}{l}\text { Name of } \\
\text { Initiative }\end{array}$ & $\begin{array}{l}\text { Type of } \\
\text { Regulation }\end{array}$ & Compliance & Usage \\
\hline $\begin{array}{l}\text { Sphere } \\
\text { Humanitarian } \\
\text { Charter and } \\
\text { Minimum } \\
\text { Standards in } \\
\text { Disaster } \\
\text { Response }\end{array}$ & $\begin{array}{l}\text { Code of } \\
\text { Conduct } \\
\text { sanctions for non-compliance. }\end{array}$ & $\begin{array}{l}\text { No formal system of } \\
\text { membership. Sphere is an } \\
\text { open-access resource that } \\
\text { any organization or aid- } \\
\text { worker can use for } \\
\text { guidance. }\end{array}$ \\
\hline HAP & Certification & Certification granted for three & 91 member organizations \\
\hline
\end{tabular}




\begin{tabular}{|c|c|c|c|}
\hline $\begin{array}{l}2010 \text { Standard } \\
\text { in } \\
\text { Accountability } \\
\text { and Quality } \\
\text { Management }\end{array}$ & Scheme & $\begin{array}{l}\text { years, subject to an extensive } \\
\text { audit and mid-term } \\
\text { monitoring. Certification can } \\
\text { be revoked if a complaint } \\
\text { about a member's conduct is } \\
\text { upheld by the Standing } \\
\text { Complaints Committee. }\end{array}$ & $\begin{array}{l}\text { from across the world, } \\
\text { including } 17 \text { fully- } \\
\text { certified members. }\end{array}$ \\
\hline
\end{tabular}

\section{METHODOLOGY}

Thirty-four participants with responsibility for accountability policy were selected from a sample of fourteen NGOs that bear similarities in terms of the global reach of their programs, annual turnover and association with HAP and/or Sphere. These individuals represent an expert community that has emerged to manage the increasing demands on NGOs to demonstrate accountability. They have been intimately involved in important shifts in the understanding and practice of accountability, and they have unique experiences of the challenges of implementing peer regulation initiatives. In the words of one interviewee:

'...you get a good sense of what's going on in the sector by looking at the jobs market. And in the last five years, these Accountability Managers have been popping up left, right and centre. Accountability Advisers, Accountability Managers, Heads of Accountability. And now a lot of the organizations are recruiting Heads of M\&E. Heads of Planning, Monitoring and Evaluation. Heads of Research and Evaluation. I think that's where they're seeing the real challenge' (Int.5). ${ }^{\text {iv }}$

These job titles match or closely correlate with the roles of the research participants. Semistructured interviews were conducted between November 2011 and March 2013. Participants were asked to comment on the effectiveness of peer-regulation based on their professional experience and awareness of trends in the wider sector. The paper primarily focuses on their responses with regard to HAP and Sphere. The research was supplemented with interviews with individuals from NGO membership bodies, independent consultants with expertise in NGO accountability, and document analysis. Some quotes in this report are directly attributed to named persons with their consent. Most participants requested that their identity remain confidential. The anonymous quotes have been framed in a generic way where it is felt that it 
would be helpful to place the comment into context (e.g. 'a staffer from a HAP-certified NGO stated that...'). All such references have been approved by the relevant interviewee.

The interview data was coded by hand. What follows is a summary of the key themes, divided into two main sections: the benefits afforded by peer-regulation, and the associated challenges. Most of the commentary relates to the latter, which reflects the disproportionate focus of most of the interviewees' responses.

\section{PERCEIVED BENEFITS OF PEER-REGULATION}

\section{Catalyst for change}

HAP and Sphere were forged by an extensive consultative process, which has helped to bestow legitimacy on the initiatives. They represent the distillation of a rich body of expertise in humanitarianism. There was almost unanimous agreement that one of the greatest benefits of peer-regulation is that it generates intra-organizational momentum for change. Participants find the initiatives extremely valuable in raising the profile of accountability issues amongst their fellow staff-members. The wide recognition of the initiatives helps to validate their efforts to promote new ways of conceiving accountability. Further, the participants found that Sphere or HAP were particularly effective levers for reform once their organization had pledged to abide by the standards. A rhetorical commitment to the initiatives helps to energize discussions about how they can be translated from abstract principles to operational reality. It helps to shape perceptions of the level of service that affected communities are entitled to expect and can instigate meaningful changes in practice. All of the NGOs had internal accountability frameworks that had been shaped to some extent by norms associated with peer-regulation, which attests to the success of the initiatives in setting the policy agenda. Indeed, several participants identified concrete examples of reform that could be directly attributed to the influence of HAP and/or Sphere; including Oxfam's establishment of complaints mechanisms and an open information policy, and Merlin's introduction of a protection policy for vulnerable individuals. There was consensus that one of the most valuable benefits of peer-regulation are the diverse learning opportunities; including training workshops, tools for policy gap analysis, case study materials, discussion forums and informal networking. Both HAP and Sphere were applauded in this respect, and one interviewee observed in terms of the former: 'the conversations that I've had with a number of people whose organizations have been involved in the certification process, the 
certification aspect of HAP is for a lot of people...secondary to the kind of identification and sharing of good practice that HAP has done' (Int.5). The remark alludes to an undercurrent of cynicism about certification, which is discussed in more detail below.

\section{Signal of credibility}

Participants admitted that one of the main motivations for observing peer regulation initiatives is to enhance donor confidence that funds will be spent wisely. Moreover, NGOs are more likely to become involved when peer organizations proclaim adherence to the initiatives, for fear that otherwise they would be in a disadvantageous position in the competition for funds. Both HAP and Sphere promise reputational advantages to NGOs, but participants conceded that HAP is the most highly regarded because of its stringent requirements for certification. HAP's endorsement is seen as one of the most powerful signals of an organization's credibility both within and outside the sector. The terms 'brand recognition' and 'kite-mark' were used by some participants to describe the attractions of HAP membership, which suggests that NGOs have emulated the corporate sector in advertising their accountability credentials, as the following quote reveals:

'HAP also comes with a bit of a PR slant to it, so it enables us...to sell ourselves....That brand bit is actually massively influential, I think, and I certainly know from [our organization's] position and the views of our Chief Executive - the moral argument to be accountable is clear and, you know, we're fully behind it, but in HAP the reason that we are going for certification is for the recognition of the work that we're doing.' (Int.21)

\section{PERCEIVED CHALLENGES OF PEER-REGULATION}

\section{Bound in a web of regulation}

HAP and Sphere are embedded in a complex and diverse regulatory terrain that NGOs have to navigate to access funding. It is not possible to fully appreciate the challenges associated with HAP and Sphere without understanding how the diverse demands of this multifaceted regulatory regime intensify pressures to demonstrate compliance with sector-wide norms. Practically all of the participants expressed concerns over the recent proliferation of regulatory initiatives, which one person described in pejorative terms as 'an industry of 
standard-setting' (Int.2). Participants complained of being overwhelmed with trying to meet the reporting requirements and keep abreast of the latest developments; and several described a wearying feeling that: 'there always seems to be a new initiative popping up' (Int.20). An interviewee from Oxfam explained that field-workers 'feel that there are too many of these initiatives - that's feedback that we get quite often, and they're saying, well should we be doing HAP, should we be doing this, should we be doing that' (Int.4).

It is hard to promote the accountability agenda in a climate where practitioners feel inundated with standards and guidelines, since they may become disengaged, and inclined to dismiss attempts at organizational reform as 'just another new initiative, rather than an integral part to what they should already be doing' (Int.7). The risk is that peer-regulation is perceived as a confusing and burdensome policy fad. A former board-member of Sphere recognized that these reactions were commonplace and understandable given that: 'they'd be lucky to get a half-hour briefing on quality and accountability generally before being sent out to the field...they are beyond saturation point in terms of standards and principles and commitments and frameworks' (Int.31). The delivery of comprehensive training programs is logistically challenging when emergencies require rapid deployment to the field, and it is also a resourceintensive proposition given increasingly mobile workforces.

The scope of different regulatory initiatives can overlap, which exacerbates the confusion. Indeed, a representative from HAP acknowledged during a General Assembly of member organizations that: '[m]any of us have been asked what is the difference between [HAP and Sphere] and there is no clear answer to this' (HAP, 2008: 12). The accountability requirements relating to both initiatives also overlap with other peer regulation schemes, which means that basic information about performance and impact is often recycled to fit various reporting formats. Moreover, donors frequently tie their funding streams to accountability benchmarks of their own design, meaning that information has to be mined from peer regulation reports rephrased to meet the donor's preferred format. This duplication of effort was roundly criticized by interviewees as inefficient and wasteful.

Participants suggested that accountability priorities of NGOs tend to be biased towards donors, rather than affected populations. This can be directly detrimental to the ability of NGOs to adhere to their missions: 'Field-staff almost have to choose are they going to write reports to donors and fill out a log-frame...or are they going to go and listen and respond to what poor people are saying' (Int.6). A staffer suggested that donor insistence on the use of 
their own accountability criteria revealed that: 'donors...do not [want] to encourage us to formulate around single areas, or single ideas or single standards, because that in some way would compromise their own control. DFID is a classic example of this...massively supportive of HAP and Sphere and all those kinds of things - but don't put their money where their mouth is, but also want to set up their own systems for checking that we are accountable' (Int.21). A senior figure from World Vision called for 'a much more sophisticated, more profound, more respectful dialogue with donors' (Int.8) to explain the implications for overheads on preparing several unique reports, a largely unproductive exercise if it revises information already in the public domain. It adds a further layer of complexity to the NGO regulatory environment that aims to satisfy donor preferences, rather than the needs of affected populations. It is difficult, however, to initiate honest conversations with donors in a highly competitive environment for funding, which places pressure on NGOs to publicize their (occasionally embroidered) accounts of successful impacts. As Alex Jacobs, the Director of Programming and Effectiveness at Plan International, observes: 'in organizations, you only really get change when you get survival anxiety. NGOs...survival anxiety is around keeping the donors happy, and so senior managers' attention has to be focused on that.' The Director of the Consortium of British Humanitarian Agencies, Sean Lowrie, also identified the financial dependence of NGOs on powerful stakeholders as a fundamental problem. Reflecting on his extensive professional experience, he argued that that donor influence poses severe limitations on the potential to deliver radical reform: 'the only way to redress the power imbalance is to change the business model, to change the political economy. So I would argue that NGOs, being independent organizations, could probably reinvest the money from quality and accountability initiatives into acquiring independent funding without strings... because without that, they can’t respond to local influence.'

\section{Bureaucratic overload}

The combined pressures of donor accountability and peer-regulation place significant demands on human resources. Nearly all of the participants expressed fears that staff attention, which could be spent on endeavors that could arguably contribute more meaningfully to accountability, is instead spent on the time-consuming task of documenting performance. They did not object to formal reporting procedures per se; rather, they were concerned that excessively bureaucratic procedures limit the extent to which accountability 
mechanisms can assist the organization in developing meaningful relationships with affected communities. In a highly-pressurized and resource-constrained environment, onerous reporting procedures can be regarded as a maddeningly tedious ritual; in the words of another interviewee, 'just another thing to fill in' (Int.2). These qualms were most often linked to HAP, with its strong focus on compliance and verification. The challenge, explained by a participant from a HAP-certified organization, is striking an appropriate balance: 'I know we have to do reporting and we've got the auditors coming in and we've got all these other things, but for me I want to make sure...that the priority is actually delivering the work rather than just reporting on it' (Int.28). Likewise, an Oxfam staffer cautioned that: '...it does risk turning into a paper trail auditing exercise and the actual principles of listening to the people you're seeking to serve can get a little bit lost' (Int.26).

The drain on staff time may not be immediately apparent. Although there was consensus that peer-regulation provided valuable opportunities for networking and sharing of best practice, several suggested that opportunity costs should be factored into the amount of time that has to be spent serving on working groups, attending meetings and developing learning resources.

Given that peer-regulation can be a labor-intensive commitment, several of the interviewees expressed disappointment that the claims made in favor of the initiatives have not been clearly substantiated with evidence of positive impact. Two participants related that the cost associated with implementing policies in accordance with the initiatives had increased internal pressure on them to justify the expenditure by identifying the concrete benefits that accrue from membership. This challenge cannot be underestimated given that the representatives of HAP and Sphere have admitted that data on the impact of the initiatives is scarce (ALNAP, 2012). A senior NGO adviser voiced his frustrations about a recent meeting that he had attended where HAP and Sphere representatives acknowledged that they had:

'...no evidence of the impact of these things...So what's the justification for allocating funding for accountability purposes? What is the business case for that?...That Sphere and HAP are standing up... and saying that we don't know - we don't have any evidence in terms of impact - that's shocking actually' (Int.12).

Ironically, the initiatives have yet to provide the levels of accountability that are regularly demanded from NGOs. HAP and Sphere have not been in a position to provide a level of information about their impact that some respondents feel would be sufficient to evaluate the effectiveness of peer-regulation. John Damerell, the Project Manager from Sphere has 
claimed that although '[w]e're unable to determine directly if Sphere has had an impact in improving humanitarian work...there is a widespread perception that it has had a beneficial effect' (ALNAP, 2012: 79). Likewise, Smruti Patel of HAP has acknowledged that '[w]e do need to be more rigorous in evidence-gathering' but that 'anecdotal evidence suggests HAP standards are making a difference' (ibid: 82; also see Blagescu, 2010: 3). Practically all interviewees expressed similar sentiments.

\section{Organizational diversity}

Most of the leading international NGOs have a federal system of governance, where member organizations in different countries enjoy varying degrees of autonomy under the same institutional 'umbrella'. Participants in such NGOs explained that issues of organizational structure could be significant barriers to full engagement with peer regulation initiatives. In the words of a participant from ActionAid: 'one of the challenges that we find in terms of compliance with some of these peer regulation mechanisms is that it by default assumes that there's that kind of traditional hub and spoke model and that it's quite easy to then demonstrate accountability because you've got common and consistent systems and approaches and ways of delivering' (Int.20). Federal NGOs are afflicted with problems of synchronization in all spheres of operation. The headquarters or international secretariat can have limited information or control over the conduct of member organizations, meaning that it is extraordinarily difficult to coordinate accountability policy, much less monitor performance. A participant from a centralized organization described the tasks associated with HAP membership in favorable terms, in comparison with the experience of counterparts in federal NGOs. Despite the fact that the latter tend to have more resources at their disposal:

'...because of their huge size and scale, the assurance over maintaining that certification must be an absolute nightmare for them, I don't know how they do it...And speaking to the likes of [three leading federal NGOs] who have that kind of family of organizations, I know that one of the things that they struggle with is... agreeing across all of them to have a global approach is really lengthy and difficult. And obviously there are politics between the family members as well, and it gets very complicated, so in some ways I'm quite pleased that I work for a single-entity organization, it's much easier...it's actually quite an easy organization to influence' (Int.21). 
It is relatively simpler for NGOs with a centralized system of governance to collate information about accountability performance for reports to donors and to peer regulators, because they have greater organizational cohesion. Participants who had past experience with centralized organizations, and who were currently employed by federal NGOs, also confirmed that they had previously found it easier to focus the minds of their colleagues on policy changes, and to implement accountability consistently.

Participants from NGOs that work exclusively through partners remarked that HAP benchmarks were not always appropriately tailored to their needs, as illustrated by the following excerpt: 'HAP was expecting us to work with all of our partners on accountability and training all of our partners. But we have about 500 and this is just not going to be possible...we've said, no, that's never going to happen...in some respects I think the approach is more suited for operational agencies rather than those that work through partners' (Int.28). HAP has been useful in promoting a vision of accountability from the standpoint of affected communities, but the reality is that NGOs 'cannot force a partner to work that way' (Int.20). Fruitful partnership is felt to rest upon principles of respect and mutual learning, which might be jeopardized by heavy-handed insistence upon observance of the finer details of HAP (quite apart from the obvious logistical difficulties in rolling out a training program and monitoring compliance across miscellaneous organizations). A participant in an organization with a large partner network noted that awkward predicaments could arise when partners had little appreciation of accountability norms: 'a lot of the countries where we operate have very hierarchical culture...If you're a West African middle class man, the idea that you actually listen and care about what a peasant farming woman has to say to you is a bit of a shift in attitude' (Int.26). Nonetheless, the interviews yielded other anecdotes that underlined that partners can 'be more accountable and not HAP-certified' (Int.30) in terms of maintaining a close and long-term relationship with the local community. Partners can be more appreciative of customs and culture, and have a greater awareness of their needs and preferences through engaging in continual dialogue with community members. It is important, then, to 'avoid locking [peer-regulation] into some Geneva-based ivory tower, rather than a more inclusive outreach to Southern society' (Int.26).

In sum, the management challenges faced by organizations in the sector are very diverse, and there is a feeling that peer regulation initiatives should be flexible enough to accommodate this organizational complexity. The participants believe that it is vital to explain to donors 
that expectations about accountability should be tailored according to what is feasible for NGOs to deliver.

\section{Embedding a culture of accountability}

Interviewees that were supportive of certification schemes doubted whether a profound cultural shift in accountability could be achieved if peer regulation initiatives symbolized nothing more than a paper commitment. HAP's bid for legitimacy largely rests upon monitoring the activities of its member organizations and imposing penalties for noncompliance. It was widely acknowledged that donors were inclined to consider HAP as a credible signal of an organization's integrity because of its robust verification procedures. Some interviewees with experience of HAP believed the potential of increasing the organization's attractiveness to donors helped to motivate staff to take the accountability agenda seriously. Some related how the pressures of collating evidence of good practice in time for an audit had galvanized people into speeding up a process of reform that may have otherwise stagnated.

However, most participants had misgivings about HAP's compliance-based model, which could risk fostering a technocratic, 'tick-box' mentality towards accountability. These views were expressed by participants with and without direct experience of HAP certification. They suggested that it can raise anxiety amongst practitioners about the documentation of impact and performance, and dilute attention from the lived realities of affected populations. An example is HAP's promotion of feedback procedures, such as complaints boxes and noticeboards, which enable communities to voice their dissatisfaction about the poor performance of NGOs. Although hailed by some as a watershed in NGO accountability, a skeptical participant noted that such mechanisms can be used in an instrumental manner in the context of an accountability culture excessively focused on reports:

'I believe that you can be accountable without having a complaints mechanism - and if you have a complaints mechanism, it doesn't mean that you're accountable. But because we can measure whether we have a complaints mechanism or not, because we can employ staff to run the complaints mechanism, because we can quantify it in large proposals - we do it' (Int.30). 
The danger of HAP's model of accountability, founded on routine verification, is that it may have the unintended consequence of tempting its members to pursue tokenistic policies that can be portrayed in written reports as examples of good practice.

Furthermore, there was some hostility towards the implicit threat of sanctions (such as the withdrawal of certification for non-compliance), which was seen as deleterious to efforts to foster a culture of openness. In the words of one participant: 'I think the danger with that is that you'll talk up your work and you won't be honest about the things that actually go wrong' (Int.22). Another participant admitted that learning was undermined across the sector because 'we're kind of terrified of fuelling bad publicity which will directly affect our income' (Int.6). Beris Gwynne, Director for Global Accountability at World Vision, agreed that: 'donors, whether they are private or government, have very little tolerance for being told that somebody has made a mistake.' The potential loss of certification, and the adverse attention that such a penalty would be likely to attract, could be a powerful disincentive to disclosure. Transparency, however, is essential to organizational learning, and improvement in performance is unlikely to be achieved if organizations feel inhibited from discussing their shortcomings. A staffer identified this issue as one of the most frustrating aspects of the job: 'I want more bad news stories, because agencies never share when they're getting stuff wrong' (Int.28).

Nearly all of the participants argued that peer-regulation was not sufficient to inculcate higher standards of accountability. There needs to be a fundamental attitudinal shift at all levels of the organization regarding the nature of their responsibilities towards the people that they seek to represent and serve. According to a senior figure at Oxfam: 'The problem is we're stuffed full of people who want to do good, and because they want to do good assume that they are doing good' (Int.26). Nonetheless, recent examples of NGO behavior in crisis situations may indicate that the accountability norms have not been fully internalized by key agents within leading organizations. Nick Guttman, the Head of the Humanitarian Division in UK-based Christian Aid, described the exclusion of local people from the Haitian relief effort as an illustrative example:

'...a cursory comment, a chat to someone who puts themselves forward and perhaps a local person invited to a meeting and that's often seen as accountability. So many organizations talk the talk about accountability and including local people in decisions that affect them. But in Haiti local people were not part of the decision-making process despite all the talk. 
Much of this comes down to individual and organizational attitudes not to the agreed principles and standards that they are signed up to. These attitudes, sometime probably from organizations certified by HAP - result in the agreed principles and standards about local accountability and inclusion being thrown out of the window when it comes down to the new high-profile, high-intensity emergencies. Because it's not ingrained, it's not part and parcel of the culture, it's not part of the psyche.'

Some participants described a certain air of arrogance that persists in some parts of the humanitarian sector; an attitude of 'we know best' and a sense of impatience at having to perform the ritual of community consultation when the best or most feasible way to deliver programs seems obvious. A participant argued: 'it's certainly not conscious, it certainly not a conscious effort to exert power over the poorest in the world. It's just a cascade of wellintentions' (Int.30).

Peer regulation initiatives can be thought of as a weathervane that indicates the changing direction of debate in the sector about accountability norms. The debate will remain relatively superficial until the norms permeate the organizational culture, become embedded in daily practice and are fully absorbed by those that manage and deliver humanitarian aid. Staff should therefore be encouraged to reflect upon their motivations for engaging in humanitarian work, and the nature of the relationships that they forge with partners and communities.. Most participants stressed the importance of strong leadership on accountability from a senior level. Equally, they acknowledged that field-staff should attach real value to efforts to involve communities at each stage of the design, implementation and evaluation of humanitarian assistance. A former chair of Sphere had modest expectations about the potential of peer regulation initiatives to promote such a profound transformation:

'I have come to the conclusion that accountability to beneficiaries can't become, and mustn't become, a hard bureaucratic requirement. Because then you lose the essence and the meaning and the humanity that is about accountability to beneficiaries....I think it needs individuals to make it happen. And individuals will make it happen when they realize that it's fundamentally important, from a rights, from a human dignity, from a humanity perspective.' (Int.31) 
This research has yielded some candid insights from key informants into the various impacts of peer-regulation on humanitarian action. Several broad themes are apparent from the interview data. It is evident that participants value the contribution of HAP and Sphere in setting a common agenda on accountability, and providing momentum for change. The initiatives have helped to diffuse norms about the rights of affected populations to live a life with dignity, and to be consulted about the provision of assistance. Peer-regulation has strengthened networks between NGOs and facilitated the sharing of organizational learning. Participants also acknowledged that the initiatives can help assure donors of the integrity of their organizations. HAP membership is a particularly useful tool to showcase the accountability credentials of a NGO.

The benefits of peer-regulation are counterbalanced by a rather daunting list of challenges. There are serious concerns about the workload that the initiatives can entail, particularly in the context of donors that insist upon receiving separate reports tailored for their purposes. Several participants were alarmed about the increasing bureaucratization of HAP, and felt that an excessively technocratic approach to accountability could be counterproductive to the broader mission of being responsive to affected communities. Further, participants complained that standards should not be expected to apply equally to organizations with radically different structures and working practices. NGOs face complex challenges in promoting accountability, depending on whether they are centralized organizations, have a federal structure, and/or work with partners. It was suggested that HAP's verification and compliance criteria are rather too rigid to accommodate this organizational diversity. Finally, participants reflected that deep-rooted cultural change is necessary across the sector before the vision of humanitarian accountability promoted by HAP and Sphere can become reality.

Significant changes in peer-regulation are underfoot. Discussions are underway to integrate HAP with another peer regulation scheme that focuses on human resources: People in Aid. The 'Core Humanitarian Standard' (CHS) aims to bring 'greater coherence to standards in the humanitarian sector' (CHS, 2014), which might go some way to addressing the participants' concerns about regulatory overlap. The proponents of CHS have conducted a wide survey of stakeholders about the efficacy of peer-regulation to determine the shape of the new initiative. The following policy suggestions are based on the interview data and ventured as a contribution to the ongoing discussions: 
- The sector should find collective ways of engaging in honest dialogue with donors about the impact for overheads of preparing unique reports, in addition to peerregulation commitments. A collective effort would minimize the possibility that individual organizations would be 'punished' by donors for objecting to their accountability demands.

- Creative thinking is needed about the different ways that accountability can be demonstrated, other than through paper documentation. New media could be further exploited (e.g. capturing examples of good practice through mobile-phone footage, SMS, and Facebook posts, as long as privacy/ethical concerns are respected). It is inevitable that compliance-based initiatives such as HAP will involve significant paperwork, but the reflex bias towards detailed written evidence should be challenged wherever feasible.

- HAP standards should be interpreted and applied in a more flexible way; customized for organizations that grapple with complex challenges in coordinating accountability policy. Nonetheless, it is HAP's role to push reluctant organizations to achieve better standards of performance. The plea of mitigating circumstances by some NGOs may disguise institutional inertia and hostility towards change. It would be helpful for representatives from counterpart NGOs to assess one another's performance as part of the review process, in order to filter out genuine difficulties from complaints borne out of recalcitrance.

- There is no panacea for radical attitudinal shifts towards accountability. Cultural changes take time. The trajectory to meaningful reform can be maintained by organizations if individuals are recruited who can demonstrate an appreciation of a rights-based approach to accountability.

The main limitation of this research is the small sample of participants. Expert perceptions may not accord with the views of field-workers and affected communities. It is noteworthy that the findings mainly focus on the management and administrative challenges of peerregulation, rather than the lived experiences of affected populations. This is not to suggest that the insights of the participants are less valuable than those 'on the ground', or to deny that management difficulties can ripple out to the field. It is simply to observe that the participants' assessments of the extent to which HAP and Sphere have proved 'effective' are molded by their situatedness in the elite tier of the organization. Moreover, the participants were able to say little about the experiences of small NGOs. There is evidence to suggest that 
small organizations harbor concerns that peer regulation initiatives reflect the preferences of their larger counterparts, and that they find adherence to the standards excessively onerous (Hammand \& Morton, 2011: 16). A more holistic view of the impact of peer-regulation would require complementary studies with a range of different stakeholders, including with representatives of HAP and Sphere. As noted by the participants themselves, such evidence of impact is unfortunately sorely lacking.

ALNAP (Active Learning Network for Accountability and Performance). (2012). Meeting the Urban Challenge. 27 $7^{\text {th }}$ ALNAP Meeting, Chennai, India, 17-19 January 2012:

Rapporteurs' Meeting Record. Retrieved from: http://www.alnap.org/events/27th.aspx

Bies, A.L. (2010). Evolution of Nonprofit Self-Regulation in Europe. Nonprofit and Voluntary Sector Quarterly, 39(6), 1057-1086.

Blagescu, M. (2010). The HAP Standard and Certification Scheme: Some Highlights. Retrieved from: http://www.hapinternational.org/pool/files/monica-blagescu,-speaking-notes,-29-january.pdf

CHS (Common Humanitarian Standard) (2014). The Core Humanitarian Standard. Retrieved from: http://www.hapinternational.org/what-we-do/hap-standard/the-corehumanitarian-standard.aspx

Crack, A.M. (2013a). INGO Accountability Deficits: The Imperatives for Further Reform. Globalizations, 10(2), 293-308.

Crack, A.M. (2013b). Language, listening and learning: critically reflective accountability for INGOs. International Review of Administrative Sciences, 79(4): 809-828.

Darcy, J. (2004). Locating Responsibility: The Sphere Humanitarian Charter and Its Rationale. Disasters, 28(2), 112-123.

Deloffre, M. (2010). NGO accountability clubs in the humanitarian sector: social dimensions of club emergence and design. In Prakash, A. \& Gugerty, M.K. (Eds.) Voluntary 
Regulation of NGOs and Nonprofits: An Accountability Club Framework. Cambridge: Cambridge University Press.

Dufour, C., de Geoffroy, V., Maury, H. \& Grünewald, F. (2004). Rights, Standards and Quality in a Complex Humanitarian Space: Is Sphere the Right Tool? Disasters, $28(2), 124-141$.

Ebrahim, A. (2003) Accountability in Practice: Mechanisms for NGOs, World Development, 31(5), pp. 813-829.

Edwards, M. \& Hulme, D. (1996). Beyond the Magic Bullet: NGO Performance and Accountability in the Post-Cold War World. Bloomfield, CT: Kumarian Press.

Featherstone, A. (2013). Improving Impact: Do Accountability Mechanisms Deliver Results? Retrieved from: http://www.hapinternational.org/pool/files/improving-impact-doaccountability-mechanisms-deliver-results.pdf

Gibelman, M., \& Gelman, S.R. (2001). Very public scandals: Nongovernmental organizations in trouble. Voluntas, 12(1), 49-66.

Gostelow, L. (1999). The Sphere Project: The Implications of Making Humanitarian Principles and Codes Work. Disasters, 23(4), pp. 316-325.

Gugerty, M.K. (2008). The Effectiveness of NGO Self-Regulation: Theory and Evidence from Africa. Public Administration and Development, 28, 105-118.

Groves, L. \& Hinton, R. (Eds) (2004). Inclusive Aid: Changing Power and Relationships in International Development. London: Routledge.

Hammand, L. \& Morton, B. (2011). Greater Influence, Greater Responsibility: are INGOs' Self-Regulatory Accountability Standards Effective? The North-South Institute. Retrieved from: http://www.nsi-ins.ca/english/pdf/INGOFinal.pdf

HAP (2008). HAP $6^{\text {th }}$ General Assembly, 23-24 April 2008. Approved Minutes. Retrieved from: http://www.hapinternational.org/pool/files/6th-general-assembly-approved$\underline{\text { minutes.pdf }}$

HAP (2010). The 2010 HAP Standard in Accountability and Quality Management. Retrieved from: http://www.hapinternational.org/pool/files/2010-hap-standard-inaccountability.pdf 
HAP (2012). The 2011 Humanitarian Accountability Report. Retrieved from: http://www.hapinternational.org/pool/files/2011humanitarian-accountabilityreport.pdf

HAP (2014). Members. Retrieved from:

http://www.hapinternational.org/membership/members.aspx

Jordan, L. \& van Tujl, P. (Eds.) (2007). NGO Accountability: Politics, Principles \& Innovations. London: Earthscan.

Kennedy, D. (2012). Codified Compassion: Politics and Principles in Humanitarian Governance. Unpublished doctoral dissertation. University of Minnesota, Minneapolis, MN.

Kilby, P. (2006). Accountability for Empowerment: Dilemmas Facing Non-Governmental Organizations, World Development. 34(6): 951-963.

Lloyd, R. \& Casas, L. (2005). NGO self-regulation: enforcing and balancing accountability. London: One World Trust.

Lloyd, R., Calvo, V. \& Laybourn, C. (2010). Ensuring Credibility and Effectiveness: Designing compliance systems in CSO self-reflection. Briefing Paper 127. London: One World Trust.

Najam, A. (1996). NGO accountability: a conceptual framework. Development Policy Review, 14, 339-353.

Prakash, A. \& Gugerty, M.K. (Eds.) (2010). Voluntary Regulation of NGOs and Nonprofits: An Accountability Club Framework. Cambridge: Cambridge University Press.

Sidel, M. (2010). The Promise and Limits of Collective Action for Nonprofit SelfRegulation: Evidence from Asia. Nonprofit and Voluntary Sector Quarterly, 39(6), 1039-1056.

Sphere. (2011). Humanitarian Charter and Minimum Standards in Humanitarian Response. Rugby: Practical Action Publishing. 
The Lancet. (2010). Growth of Aid and the Decline of Humanitarianism. The Lancet, 375(9711), 253.

Terry, F. (2002). Condemned to Repeat: The Paradox of Humanitarian Action. Ithaca, NY: Cornell University Press.

Tong, J. (2004). Questionable Accountability: MSF and Sphere in 2003. Disasters, 28(2), 176-189.

Walker, P. \& Purdin, S. (2004). Birthing Sphere. Disasters, 28(2), 100-111.

\footnotetext{
'These are variously referred to as self-regulatory initiatives, or quality and accountability initiatives. My use of the term 'peer-regulation' draws upon Crack (2013a).

ii An important exception is Kennedy (2012) who interviewed 60 key informants in an excellent sociological institutional analysis of HAP, Sphere and the Code of Conduct on Images and Messages.

iii Available at: http://www.spherehandbook.org/

iv 'Int' is an abbreviation of 'interview'.
} 